\title{
The human resource information system: a rapid appraisal of Pakistan's capacity to employ the tool
}

\author{
Ramesh Kumar ${ }^{1}$ Babar Tasneem Shaikh", Jamil Ahmed', Zulfiqar Khan², Sayed Mursalin², \\ Mahmood lqbal Memon ${ }^{3}$ and Shagufta Zareen ${ }^{4}$
}

\begin{abstract}
Background: Human resources are an important building block of the health system. During the last decade, enormous investment has gone into the information systems to manage human resources, but due to the lack of a clear vision, policy, and strategy, the results of these efforts have not been very visible. No reliable information portal captures the actual state of human resources in Pakistan's health sector. The World Health Organization (WHO) has provided technical support for the assessment of the existing system and development of a comprehensive Human Resource Information System (HRIS) in Pakistan.

Methods: The questions in the WHO-HRIS Assessment tool were distributed into five thematic groups. Purposively selected $(n=65)$ representatives from the government, private sector, and development partners participated in this cross sectional study, based on their programmatic affiliations.

Results: Fifty-five percent of organizations and departments have an independent Human Resources (HR) section managed by an establishment branch and are fully equipped with functional computers. Forty-five organizations (70\%) had HR rules, regulations and coordination mechanisms, yet these are not implemented. Data reporting is mainly in paper form, on prescribed forms (51\%), registers (3\%) or even plain papers (20\%). Data analysis does not give inputs to the decision making process and dissemination of information is quite erratic. Most of the organizations had no feedback mechanism for cross checking the HR data, rendering it unreliable.

Conclusion: Pakistan is lacking appropriate HRIS management. The current HRIS indeed has a multitude of problems. In the wake of 2011 reforms within the health sector, provinces are even in a greater need for planning their respective health department services and must work on the deficiencies and inefficiencies of their HRIS so that the gaps and HR needs are better aligned for reaching the 2015 UN Millennium Development Goals (MDGs) targets.
\end{abstract}

Keywords: Human resources for health, Human resource information system, Health system, Pakistan

\section{Background}

Human resources are the backbone of any national health care system. To ensure that the rightpersonnel are in the right place with the right skills, we need up to date and accurate data on human resource for health (HRH). A strong human resource information system (HRIS) helps policy makers, administrators, and managers quickly answer key questions affecting health care service delivery. It has been argued that in developing countries there are deficiencies in the availability of $\mathrm{HRH}$-specific information, and even more

\footnotetext{
*Correspondence: shaikh.babar@gmail.com

'Department of Health Systems \& Policy, Health Services Academy, Islamabad, Pakistan

Full list of author information is available at the end of the article
}

so in with regard to its consolidation, standardization, analysis, and use in the planning and managerial processes [1]. Ideally, HRIS development would begin with a systematic review and appraisal of existing data sources, mechanisms, indicators, tools, and systems in both public and private sectors. Once HRIS assessment has been carried out, the plan would proceed in a systematic manner to make decisions concerning $\mathrm{HR}$ issues [2].

\section{Global HRIS practices}

Many developing countries face daunting obstacles in meeting the health care needs of their people. One important reason is the lack of reliable and accurate data on HRH which impedes proper planning, decision

\section{Ciomed Central}


making and even the resource allocation [1]. A strong HRIS informs and enables the decision makers to address many of the key policy and management questions, which of course affect the health care delivery system. The HRIS is an important tool which is globally used by the decision makers to use data for leading and managing their HR in the health sector; however, Pakistan has been an exception [2]. The World Health Organization (WHO), through its Department of Human Resources for Health, works with the member states to strengthen their capacity for managing their health workforce, so that health services can become more and more responsive. WHO and other development agencies greatly emphasize on HR development within each country's health sector policies. Ideally, HRIS involves forging a global consensus on $\mathrm{HRH}$, by means of pursuing in-depth work in countries and building networks. There are inclusive tools to analyze and address various HRH issues in order to better assist countries. These tools lay out a general framework built in collaboration with partners, including the staff of ministries of health, health training institutions, professional associations and bilateral and international partners. Information plays a vital role in an effective management of any health system. The HRIS provides specific information support to the decision makers at various levels of the health system and assist in evidence-based decision making for an effective management of the human resources for health [3]. Appropriate use of information technology in health care depends a lot on the interest and support of the leadership in health care system. The organization needs strong leadership with sufficient means and abilities to manage the change in the organizational output [4].

\section{HRIS and the pakistani health system}

Being a low-resource country, Pakistan's health sector is facing tremendous problems in meeting the health care needs of its people, mainly because of dearth of trained HR in the rural areas where $65 \%$ of the population lives [5]. Pakistan is considered among those 57 countries which face an acute shortage of HRH. Published data suggests that one of the contributing factors to the dearth of workforce is the absence of a functional HRIS, and the subsequent incapacity for a sound HR decision making [6]. There is a lack of a clear vision, policy, and strategy for $\mathrm{HRH}$, and since the Government of Pakistan has devolved the Federal Ministry of Health after a constitutional amendment in 2011, the importance and need of a HRIS strategic plan with a clear breakdown of short term, medium term, and long term targets has become more noticeable. HRIS was never integrated within the National Health Management Information System (NHMIS), a system which was designed to generate the information on the status of ongoing health-related activities. NHMIS was supposed to facilitate evidence-based decision-making and an effective management of health care system at all levels. Traditionally, the focus in information systems has been merely on the technical aspects of the health services. However, recently the data regarding HR has been recognized as an important factor in the information systems [7].

For all the national programmes of health, implementation largely lies with the provincial governments, with an extensive network of nearly 10,000 service outlets at the district level: primary, secondary and tertiary. The Executive District Officer Health (EDO-H) is in charge of the district and is responsible for delivering promotive, preventive and curative services through the outreach workers and the primary care district facilities. The managers of all public sector hospitals in the district, report to EDO-H [8]. The efficiency of the entire system, however, ultimately depends on a robust information system, quality of data generated and the effective use of evidence for decision making [9].

The total number of health workers in public sector alone is more than 250,000. There are 448 medical schools, which produce more than 16,000 different categories of health workers [5]. These numbers, however, have been challenged multiple times and their credibility is doubtful. The HRIS in Pakistan suffers from lack of efficiency as well as usefulness. This information system also lacks coherence and integration in terms of Pakistan's HR data gathering process [10]. After the 2011 reforms, the responsibility of data management was entirely delegated to the provinces. The HR data is now collected in the routine District Health Information System (DHIS). Therefore, the provincial governments now ought to strategize the mapping, recruitment, deployment and fair distribution of HRH, which is vital to strengthen the health system [11].

\section{Study objectives}

With this background, the present study was designed. The objectives of the study were threefold: (i) to document as to how HR information is currently being collected, managed and reported; (ii) to identify the gaps related to $\mathrm{HRH}$ information that need to be urgently addressed; and (iii) to suggest the tools and processes for managing HR data.

\section{Methods}

\section{Study design}

This was a cross sectional quantitative study for which data was collected from the key stakeholders and informants, using a self-administered structured questionnaire. Observations and examination of HRIS records were also done simultaneously in order to extract the information required.

\section{Sampling frame and size}

Data was collected from all the public and private institutions across the country (65 in all), managing a HRIS. A total of 65 stakeholders involved in HRIS from public 
and private sector; including from Karachi, Hyderabad, Tando Muhammad Khan and Jamshoro in Sindh, Quetta and Mastung in Baluchistan, Lahore, Jhang, Sheikhupura, Gujranwala, Faisalabad, Kasur and Nankana in Punjab, Mardan and Peshawar in Khyber Pukhtunkhwa /FATA province, Bagh and Muzzafarabad in Azad Jammu \& Kashmir, and Islamabad. Majority of these (41) were from public sector that represented the district/ provincial health offices, tertiary level care hospitals, DHIS cell and primary health care centers; while 24 institutions were from the private sector that included hospitals, international NGOs and donors.

Principal Investigator trained the data collectors before the start the data collection process; all of them were experienced public health researchers. These data collectors then personally handed over the self-administered questionnaire to the respondents and clarified the respondents' queries. Out of the 65 institutions surveyed, twentythree (36\%) were in Punjab Province, ten (15\%) in Sindh, ten (15\%) in Baluchistan, eight (12\%) in Azad Jammu \& Kashmir, eight (12\%) Khyber Pukhtunkhwa and six (10\%) represented Federal capital Islamabad. The cadres of the respondents varied from Director General of Health to Director Provincial Health Development Centers. There were Provincial Managers of the national programmes and Chiefs of HMIS cells. The survey responses also included those of local hospital administrators and senior officials representing nongovernmental organizations (NGOs) and other development organizations. However, the answers did not have much of the difference, and therefore no significant association was found with any special cadre.

\section{Data collection}

The period of data collection was two weeks (1-15 November, 2011). The principal investigator was personally responsible for the distribution and collection of all the filled questionnaires to control and ensure the data quality. The Management Sciences for Health HRIS assessment tool was used for the data collection [12]. A self-administered questionnaire was pre-tested, and after minor adjustments mainly related to sequencing of the questions, final version was administered. The data was collected on organization information, infrastructure, HRIS software, data collection, data reporting and on the use and sustainability of HRIS. All data collected was subsequently entered in Statistical Package for Social Science (SPSS) version 17, for the purpose of analysis.

\section{Ethical considerations}

A written informed consent was obtained from all of the study participants. Ethical approval was sought from the WHO and the respective Departments of Health in all provinces of Pakistan. Information was kept confidential and anonymous during the analysis by using codes for each respondent.

\section{Results}

A descriptive analysis of the data was conducted in order to ascertain the variety and gravity of HRIS issues. A total of 65 facilities were covered. Twenty- four district health offices, 13 large hospitals, 12 private hospitals, nine DHIS "cells" were included and the rest were primary health care centers and the donors' organizations.

In $54(83 \%)$ of cases, a clerk oversaw the HRIS. Twentyfive $(38 \%)$ institutions reported having one computer. Twenty-six (40\%) institutions reported having less than four functioning computers and fifty-five (85\%) institutions reported having a functional printer. In 23 (35\%) institutions, the staff members trained in HRIS numbered less than two staff members were found to be trained.

\section{Institutional arrangements for HRIS}

When inquired about the institutions' arrangement for running and maintaining the HRIS, it was reported that there was an independent HR section in about half of the institutions; however, most of these did not have the internet facility, and even a mobile phone device. Moreover, most organizations do not have the HRIS built in their routine Management Information System (MIS). Table 1 shows the details of institutional arrangements.

\section{HR Policy, planning, coordination and capacity}

Only in three facilities (5\%), the respondents reported to have a separate staff for HR planning. Although 45 facilities

Table 1 Institutional arrangements for HRIS ( $n=65)$

\begin{tabular}{|c|c|}
\hline Independent HR Section in office & $55 \%$ \\
\hline Internet facility & $29 \%$ \\
\hline Mobile phone & $18 \%$ \\
\hline Separate computer room in office & $54 \%$ \\
\hline Backup power supply to run computers & $54 \%$ \\
\hline Trained personnel for HRIS & $72 \%$ \\
\hline HRIS as part of general MIS & $20 \%$ \\
\hline HRIS policy manual available & $20 \%$ \\
\hline HR indicators used for data collection purpose & $14 \%$ \\
\hline HR data bank available (software based) & $22 \%$ \\
\hline \multicolumn{2}{|l|}{ Type of HRIS } \\
\hline - Paper based & $42 \%$ \\
\hline - Computerized & $32 \%$ \\
\hline - Mixed & $26 \%$ \\
\hline \multicolumn{2}{|l|}{ Frequency of updating } \\
\hline - Monthly & $7 \%$ \\
\hline - Quarterly & $89 \%$ \\
\hline - Uncertain & $4 \%$ \\
\hline
\end{tabular}


(70\%) shared that HR procedures are practiced, yet a concise policy document or manual was not available (Table 2). The HR data management plan and a separate budget allocation were almost non-existent in most of the institutions (92\%).

\section{Data collection system}

Most of the institutions do not have an electronic HRIS, and therefore HR departments relied on the outdated methods of data collection such as prescribed forms and registers for data record. Data was updated when required by the higher ups or policy makers. In the majority of cases (94\%), HR data maintenance was not the responsibility of the HR section (Table 3). Data sources were also unreliable, to a large extent. Data accuracy and quality was also not up to the mark in most of the cases. Audit of data quality is not carried out on regular basis.

\section{HR data reporting and dissemination}

Most of the institutions did not have standardized HR data reporting forms available. Only ten (15\%) institutions had some software to maintain HR data. The government has been supporting the development of modern HR software, because the one in use, does not generate any analytical report. In 62 (95\%) institutions, a sample of data to be collected, was not available. Only 18 (28\%) institutions used the software to disseminate the data, on as per required basis; others relied on the paper based system. In only nine institutions (14\%), the respondents were satisfied with the performance of the software (Table 4).

\section{Human resource data use}

Only three out of 65 (5\%) institutions used the HR data regularly for decision making, planning and management for human resources. In $50 \%$ of the institutions, HR data is not demanded at all by the managers, for any decisionmaking, whatsoever. Similarly, $60 \%$ institutions did not have categories or cadres shown in their data. In $85 \%$ of institutions, HR codes did not exist (Table 5).

\section{HRIS monitoring}

Twenty percent of the institutions had a professional staff responsible for maintaining the HRIS. In 41 (63\%) institutions, it was the Director General Health who is

Table 2 HR Policy, planning, coordination and capacity $(n=65)$

\begin{tabular}{cc}
\hline HR rules and regulations & $70 \%$ \\
HR policy manual & $25 \%$ \\
Separate HR section staff at provincial level & $5 \%$ \\
Functional HR section & $20 \%$ \\
HR staff trained in data management & $10 \%$ \\
HR data management training plan & $8 \%$ \\
Separate budget for HR data management activity & $0 \%$ \\
\hline
\end{tabular}

Table 3 HR Data collection system ( $n=65)$

\begin{tabular}{|c|c|c|}
\hline \multirow[t]{4}{*}{ HR data collection methods } & Prescribed forms & $51 \%$ \\
\hline & Registers & $3 \%$ \\
\hline & Plain Papers & $20 \%$ \\
\hline & Others & $26 \%$ \\
\hline \multirow[t]{3}{*}{ HR data maintenance } & Individual files & $71 \%$ \\
\hline & Spread sheets & $17 \%$ \\
\hline & Specific software & $12 \%$ \\
\hline \multirow[t]{3}{*}{ HR data maintenance frequency } & Regularly & $17 \%$ \\
\hline & Irregularly & $12 \%$ \\
\hline & When required & $71 \%$ \\
\hline \multirow[t]{5}{*}{ HR data maintenance responsibility } & HR section & $6 \%$ \\
\hline & Individual officials & $2 \%$ \\
\hline & Separate HR staff & $3 \%$ \\
\hline & Admin staff & $57 \%$ \\
\hline & Establishment staff & $32 \%$ \\
\hline \multirow[t]{3}{*}{ HR data sources } & DHIS & $38 \%$ \\
\hline & HRIS manual & $18 \%$ \\
\hline & Others & $32 \%$ \\
\hline \multirow[t]{4}{*}{ Indicate type of HR data collected regularly } & Employee data & $35 \%$ \\
\hline & Payroll & $45 \%$ \\
\hline & Training & $14 \%$ \\
\hline & Other & $6 \%$ \\
\hline \multirow[t]{4}{*}{ Data accuracy } & Inaccurate & $2 \%$ \\
\hline & Somewhat accurate & $38 \%$ \\
\hline & Very accurate & $40 \%$ \\
\hline & Not sure & $20 \%$ \\
\hline \multirow[t]{4}{*}{ Frequency of data quality audit } & Monthly & $3 \%$ \\
\hline & Annually & $6 \%$ \\
\hline & When required & $69 \%$ \\
\hline & Don't know & $22 \%$ \\
\hline \multirow{3}{*}{$\begin{array}{l}\text { Capacity of implementation of modern } \\
\text { data collection system }\end{array}$} & Yes & $43 \%$ \\
\hline & No & $51 \%$ \\
\hline & Not sure & $6 \%$ \\
\hline
\end{tabular}

responsible to monitor the HRIS. The monitoring again was not regular in most institutions, and it was done on as per required basis $(73 \%)$. The feedback channel was found in only $20 \%$ of the cases (Table 6 ).

\section{Discussion}

Use of evidence has seldom been practiced for crucial decision making in Pakistan's health sector [13]. The overall HRIS assessment revealed a very bleak picture. The main weaknesses found were inadequate IT facilities and lack of trained manpower; weak supporting and monitoring mechanism, negligible budget and almost no maintenance. In the first instance, these issues seem to be a common 
Table 4 HR Data reporting and dissemination $(n=65)$

\begin{tabular}{cc}
\hline Standardized data reporting forms available & $15 \%$ \\
Software capable of producing analytical reports & $11 \%$ \\
Satisfaction with the performance of software & $14 \%$ \\
Samples of analyzed data if available & $5 \%$ \\
Support for developing HRIS software & \\
• Government & $62 \%$ \\
• Donors & $29 \%$ \\
• Own initiative & $9 \%$ \\
HR data transmission mode & \\
• Paper & $55 \%$ \\
- Specific software & $28 \%$ \\
• Spread sheet & $15 \%$ \\
• Online & $2 \%$ \\
HR data transmission schedule & \\
Weekly & $22 \%$ \\
Monthly & $26 \%$ \\
Annually & $3 \%$ \\
As required & $49 \%$ \\
\hline
\end{tabular}

phenomenon of the developing countries where majority of the health systems are undergoing transition. Very few studies could be found for comparison. Nevertheless, one global review of HRIS describes the findings similar to those documented by our study and concludes that HRIS practices are fragile and weak within countries because of shortage of trained human resource in health care sector [14]. Management of human resources in health sector is dependent on the timely evidence generated by an efficient, modern and functional HRIS [15]. One of the stewardship roles of the provincial governments is to build the capacity of their HRH and subsequently sustain them, to make the health system responsive to the needs of the population served [16]. The use of information technology in the management of health care workforce has been slow to start in

Table 5 Use of human resource data by the institutions $(n=65)$

\begin{tabular}{cc}
\hline HR cadre list available & $40 \%$ \\
HR codes in use & $15 \%$ \\
Demand for HR data for decision making & $55 \%$ \\
Main user of HR data & \\
$\cdot$ Facility in-charge & $50 \%$ \\
$\cdot$ HR manager & $20 \%$ \\
$\cdot$ Higher authorities & $25 \%$ \\
HR data use in decision making, planning, management & \\
• Regularly & $5 \%$ \\
• Antermittently required & $35 \%$ \\
\hline
\end{tabular}

Table 6 HRIS monitoring $(n=65)$

\begin{tabular}{cc}
\hline $\begin{array}{c}\text { Any authority or committee to monitor HRIS } \\
\text { Type of authority monitoring HRIS }\end{array}$ & $20 \%$ \\
• DG Health & $63 \%$ \\
• DHIS manager & $17 \%$ \\
• Head of HRIS cell & $20 \%$ \\
Frequency of HRIS monitoring & \\
• Weekly & $2 \%$ \\
• Monthly & $8 \%$ \\
• Annually & $17 \%$ \\
• As and when required & $73 \%$ \\
Feedback on HRIS & $20 \%$ \\
Feedback authority & \\
• Local administration & $58 \%$ \\
• Higher ups & $17 \%$ \\
• No feedback & $25 \%$ \\
\hline
\end{tabular}

most developing countries; however, the usefulness of the HRIS and its benefits in terms of better performance of any system has been realized with the advent of computers [17]. Many developing countries have benefited with the use of computer databases in the health sector and with the generation of evidence, which has eventually been utilized for effective strategic planning for an improved health system performance [18]. Continuing education and capacitybuilding initiatives for health providers are imperative for improving health care delivery in a highly pluralistic health care system in Pakistan [19]. This would be possible, only if a functional HRIS is in operation. Needless to say, that a well-developed strategic plan would provide a solid foundation for the development of a responsive health information system in Pakistan.

After the recent devolution, Pakistan does not have a national health ministry anymore, and all of the HR related functions have been devolved to the provinces. Therefore, there is a dire need to improve the reporting mechanism and data transmission from the grass root level to provide credible evidence to the provincial level for policy formulation and sectoral planning. Private organizations are still not sharing their data with public sector that creates an ambiguous state of affairs vis-à-vis actual HR number and skill mix.. It is well known that the private sector has well-trained staff with modern IT fcilities, and therefore it reflects relatively better planning, management and coordination. Public sector departments must learn from the examples and try to adapt the models.

\section{Conclusion}

Development of a comprehensive and decentralized HRIS will carry the potential of a concerted monitoring and evaluation of the HR related indicators across the health 
sector in the provinces. In view of the gaps and flaws across the departments, recorded in our study, we conclude that a well-established HRIS will facilitate data processing, report generation, transmission and feedback. Moreover, the provincial governments will be better prepared to face the challenges in order to meet the targets of the Millennium Development Goals. Given Pakistan's devolved health care system and responsibility for health service provision, it is essential that provincial governments have a functional HRIS capable of producing accurate workforce analyses, facilitating health sector planning, and enabling the development of evidenced-based HR policies.

\section{Competing interests}

The authors declare that they have no competing interests.

\section{Authors' contribution}

RK, BTS and JA designed the study. The work of data collection and database construction was distributed equally amongst RK, JA and SZ. Data analysis and interpretation was done by RK, BTS and JA. Provisional drafts of manuscript were written by RK and BTS. Intellectual inputs were provided by ZK, SM and MIM. Final revisions of draft were done by RK and BTS. All authors read and approved the final manuscript.

\section{Acknowledgements}

The team is indebted to Dr Guido Sabatinelli, WR WHO Pakistan for his valuable feedback and continuous guidance. We extend our gratitude towards all the Provincial Health Secretaries \& the Director Generals for their participation in the study. Authors thank the data collectors too for their untiring field work.

\section{Author details}

'Department of Health Systems \& Policy, Health Services Academy, Islamabad, Pakistan. ${ }^{2}$ World Health Organization, Islamabad, Pakistan. ${ }^{3}$ Health Department, Government of Sindh, Karachi, Pakistan. ${ }^{4}$ Public health Consultant, Lahore, Pakistan.

Received: 31 January 2013 Accepted: 6 September 2013

Published: 10 September 2013

\section{References}

1. World Health Organization: World Health Report 2006. Geneva: Working together for health; 2006

2. Qazi MS, Ali M: Health Management Information System utilization in Pakistan: challenges, pitfalls and the way forward. Biosci Trends 2011, 5(6):245-254.

3. Qazi MS, Ali M, Kuroiwa C: The health management information system of Pakistan under devolution: health managers' perceptions. Biosci Trends. 2008, 2(2):75-80.

4. Siddigi S, Masud TI, Nishtar S, Peters DH, Sabri B, Bile KM, et al: Framework for assessing governance of the health system in developing countries: gateway to good governance. Health Policy 2009, 90(1):13-25.

5. Hafeez A, Khan Z, Bile KM, Jooma R, Sheikh M: Pakistan human resources for health assessment, 2009. East Mediterr Health J 2010, 16(Suppl):S145-151.

6. Dayrit MM, Dolea C, Dreesch N: Addressing the Human Resources for Health crisis in countries: How far have we gone? What can we expect to achieve by 2015? Rev Peru Med Exp Salud Publica 2011, 28(2):327-336.

7. Qazi MS, Ali M: Pakistan's health management information system: health managers' perspectives. J Pak Med Assoc 2009, 59(1):10-14.

8. Nishtar S: The Gateway Paper-proposed health reforms in Pakistan-interface considerations. J Pak Med Assoc 2006, 56(12 Suppl 4):S78-93.

9. Eastern Mediterranian Regional Health System Observatory. Pakistan: Health Systems Profiles; 2012. [cited $18^{\text {th }}$ december 2012]; Available from: http://gis.emro.who.int/HealthSystemObservatory/Profile/Forms/ frmProfileSelectionByCountry.aspx.

10. World Health Organization: Pakistan. Cairo: Report of the Health System Review Mission; 2007.

11. Mazhar A, Shaikh BT: Reforms in Pakistan: Decisive times for improving maternal and child health. Healthcare Policy 2012, 8(1):24-32.
12. Management Sciences for Health: Human resource management rapid assessment tool for public and private sector health organizations. A guide for strengthening HRM System. Cambridge: A guide for strengthening HRM System; 2005.

13. Yasir I, Shaikh BT: Use of evidence for decision making: A qualitative exploratory study on MNCH Program. Pakistan: Pak J Public Health.

14. Riley P, Zuber A, Vindigni S, Gupta N, Verani A, Sunderland N, et al: Information systems on human resources for health: a global review. Hum Resour Health 2012, 10:7.

15. Fagerstrom L: Evidence-based human resource management: a study of nurse leaders' resource allocation. J Nurs Manag 2009, 17(4):415-25.

16. Shaikh BT, Kadir MM, Hatcher J: Health care and Public health in South Asia. Public Health 2006, 120(2):142-144.

17. Tansley C, Watson T: Strategic exchange in the development of Human Resource Information Systems (HRIS): New Technology. Work and Employment 2000, 15(2):108-122.

18. Spero JC, McQuide PA, Matte R: Tracking and monitoring the health workforce: a new human resources information system (HRIS) in Uganda. Hum Resour Health 2011, 9:6.

19. Shaikh BT, Rabbani F, Rahim M: Health workers for change: a tool for promoting behavior change among health providers. East Mediterr Health J 2006, 12(3/4):331-339.

doi:10.1186/1472-6947-13-104

Cite this article as: Kumar et al.: The human resource information

system: a rapid appraisal of Pakistan's capacity to employ the tool. BMC Medical Informatics and Decision Making 2013 13:104.

\section{Submit your next manuscript to BioMed Central and take full advantage of:}

- Convenient online submission

- Thorough peer review

- No space constraints or color figure charges

- Immediate publication on acceptance

- Inclusion in PubMed, CAS, Scopus and Google Scholar

- Research which is freely available for redistribution 